\title{
A Novel (Paternally Inherited) Duplication 13q31.3q32.3 in a 12-Year-Old Patient with Facial Dysmorphism and Developmental Delay
}

\author{
E. Atack ${ }^{a} \quad$ H. Fairtlough ${ }^{b} \quad$ K. Smith ${ }^{a} \quad$ M. Balasubramanian ${ }^{b}$ \\ a Sheffield Diagnostic Genetics Service and ' $S$ heffield Clinical Genetics Service, Sheffield Children's \\ NHS Foundation Trust, Sheffield, UK
}

\section{Key Words}

Duplication $13 q \cdot$ Facial dysmorphism - GPC5 - GPC6 ·

Learning difficulties $\cdot 13 q 31.3 q 32.3$

\begin{abstract}
We report a 12-year-old boy referred to the Clinical Genetics service in view of facial dysmorphism, learning difficulties and autistic spectrum disorder. 60K arrayCGH revealed an 8.2-Mb duplication on chromosome $13 q 31.3 q 32.3$, which was paternally inherited. This specific duplication on chromosome 13 has not been previously reported in the medical literature, and there are no familial or de novo patients with the same duplication breakpoints. This region contains 24 OMIM genes, including the glypicans GPC5 and GPC6, and the ZIC2 gene. We discuss the relevance of this chromosome imbalance and discuss the impact of this duplication on our patient's phenotype. Given that the duplication on $13 q$ was paternally inherited, and although initially thought to be of uncertain significance, on exploring the family history further, it became apparent that the father had learning difficulties as a child and previous surgery for congenital diaphragmatic hernia. Here we explore the phenotype in association with this novel duplication on chromosome $13 q$ and add to the existing literature on array findings within this region.

(c) 2014 S. Karger AG, Basel
\end{abstract}

Chromosome 13 is known for its paucity of genes and has long been studied for its variable phenotypic penetrance in cases of full trisomy 13 (Patau syndrome, lethal in neonates). Phenotype-genotype correlation studies involving cases of partial trisomy for segments of chromosome 13 suggest that certain trisomic regions give rise to certain phenotypes. Early reviews of partial 13q duplication cases grouped duplications as either proximal (pterq22.1) or distal (qter-22.2), assigning certain phenotypes to only one group [Rivas et al., 1984; Tharapel et al., 1986]. Duplication of the proximal part of chromosome 13 is more phenotypically variable and less studied, with possible association with severe developmental retardation and minor dysmorphic traits [Schinzel, 2001]. Clinical interpretation can be challenging, especially when reciprocal regions of monosomy are present elsewhere in the genome due to aberrations arising from parental balanced translocations [Tharapel et al., 1986; Wei et al., 2012].

High-resolution arrayCGH analyses of partial 13q duplication cases have allowed potential clinically pathogenic candidate genes to be identified. Interrogation of these candidate genes attempts to link genotype with phenotype. The clinical variability of the more established del(13)(q32) syndrome supports the possibility of further contiguous gene syndromes which encompass numerous dosage variable genes.

\section{KARGER}

E-Mail karger@karger.com

www.karger.com/msy
C 2014 S. Karger AG, Basel

1661-8769/14/0055-0245\$39.50/0
Dr. Meena Balasubramanian

Sheffield Clinical Genetics Service

Sheffield Children's NHS Foundation Trust

Western Bank, Sheffield S10 2TH (UK)

E-Mail meena.balasubramanian@ nhs.net 
Fig. 1. Facial appearance of the proband (a) and father (b), demonstrating similar facial dysmorphism including wide, elongated palpebral fissures, a prominent nose and elongated columella of the nose.
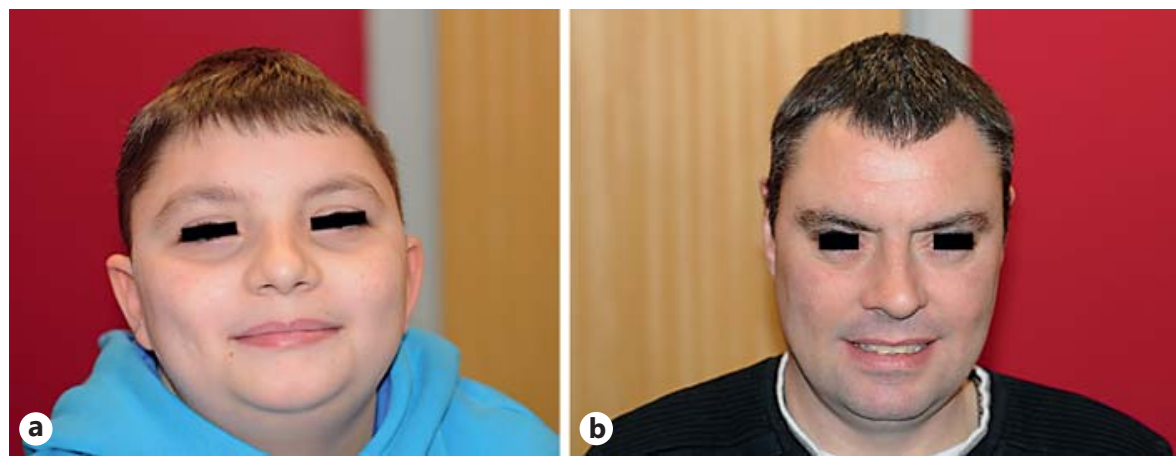

Here we present a father and son, both with a dup(13) (q31.3q32.3) identified by $60 \mathrm{~K}$ arrayCGH. This region contains 24 duplicated OMIM genes; 2 of them, GPC5 and GPC6, belong to the glypican family of genes. We explore the family history and discuss the relevance of this duplication and how this might contribute to the phenotype. We further discuss the differences in the clinical phenotype between the proband and his father, and their duplication in relation to others in the published literature.

\section{Materials and Methods}

ArrayCGH was performed on genomic DNA extracted from peripheral lymphocytes from our proband and his father. This was applied to Oxford Gene Technologies 60 mer oligo-array, printed in $8 \times 60 \mathrm{~K}$ International Standard Cytogenomic Array (ISCA) Consortium configuration, according to manufacturer's instructions, using Promega pooled control DNA as a reference (Promega Corporation, Madison, Wis., USA). Slides were scanned using a Genepix Personal 4100A scanner (Axon Instruments) and analysed using BlueGnome BlueFuse-Multi (Version 3.0) analysis software (BlueGnome, an Illumina company, Cambridge, England, UK).

\section{Clinical Phenotype}

The proband is a 12 -year-old boy referred to the Clinical Genetics service with learning difficulties, autistic spectrum disorder and unexplained muscle cramps with no evidence of a myopathy. $\mathrm{He}$ is the second child of healthy, nonconsanguineous White European parents. His mother had a previous miscarriage at 10 -weeks gestation and a still birth of unknown cause at 7-months gestation. He has an older sibling who is fit and well.

Antenatal scans of the proband were reported as normal, and there were no concerns during the pregnancy. He was born at term with a birth weight of $3.28 \mathrm{~kg}$ (9-25th centile) and was well immediately after birth. He showed developmental delay; he sat up at 18 months of age, walked at 2 years of age and was delayed with his speech. He currently attends a mainstream school but is scheduled to attend a secondary school for children with learning disabilities. He had previously been examined by the Paediatric Neurology department in view of muscle cramps, but all results of metabolic studies were reported as normal.

On examination, he showed a dysmorphic appearance, including elongated, wide palpebral fissures, elongated columella, bilateral low-set ears, short-webbed neck, and a box-shaped body habitus. His growth parameters at 12 years of age included height of $144.6 \mathrm{~cm}$ (25th centile), weight of $48.7 \mathrm{~kg}$ (91st-98th centile) and head circumference of $51.5 \mathrm{~cm}$ ( 0.4 th-2nd centile).

On further enquiry, following the knowledge that this duplication was paternally inherited, his father was also noted to have similar dysmorphism (fig. la, b). His growth parameters were height of $164 \mathrm{~cm}$ (2nd-9th centile), weight of $66.6 \mathrm{~kg}$ (25-50th centile) and head circumference of $55 \mathrm{~cm}$ (9th centile). His father had mild-moderate learning difficulties as a child but was now living independently with his family. Interestingly, he was diagnosed with a congenital diaphragmatic hernia, which needed surgery 17 days after birth.

\section{Results}

$60 \mathrm{~K}$ arrayCGH was performed as part of ongoing investigations to identify a cause for the proband's learning difficulties. This showed an $8.2-\mathrm{Mb}$ duplication on chromosome 13q31.3q32.3 between basepairs 92,776,868 and 101,047,505 (genome build GRCh37) confirmed as being paternally inherited (fig. 2).

The duplication contains 29 genes (listed here from q31.1 to q32.3); GPC5, GPC6, DCT, TGDS, GPR180, SOX21, ABCC4, CLDN10, DZIP1, DNAJC3, UGGT2, HS6ST3, OXGR1, MBNL2, RAP2A, IPO5, FARP1, RNF113B, STK24, SLC15A1, DOCK9, UBAC2, GPR18, GPR183, TM9SF2, CLYBL, ZIC5, ZIC2, and PCCA. Of these, 24 are OMIM genes (all of those listed above excluding TGTS, CLDN10, RNF113B, UBAC2, and ZIC5).

The 24 OMIM genes were ranked according to their haploinsufficiency score (HI score). Since the probability of haploinsufficiency considers the dosage sensitivity of a 
Table 1. Duplicated OMIM genes (HI scores of <15) in the region of duplication [genome build Hg19/GRCh37]

\begin{tabular}{lll}
\hline OMIM gene, No. & HI score* & Description \\
\hline ZIC2 \#603073 & 4.9 & cerebellum protein \\
SOX21 \#604974 & 10 & expressed in mammalian brain \\
PCCA \#232000 & 11.1 & mutations cause propionic acidemia \\
GPC5 \#602446 & 11.5 & modulate morphogens such as sonic hedgehogs (SHHs) and ZIC2 \\
GPC6 \#604404 & 11.5 & MAP kinase pathway \\
STK24 \#604984 & 12.2 & morphogen (mouse models only) \\
HS6ST3 \#609401 & 14.7 &
\end{tabular}

* 1 = high, 99 = low.

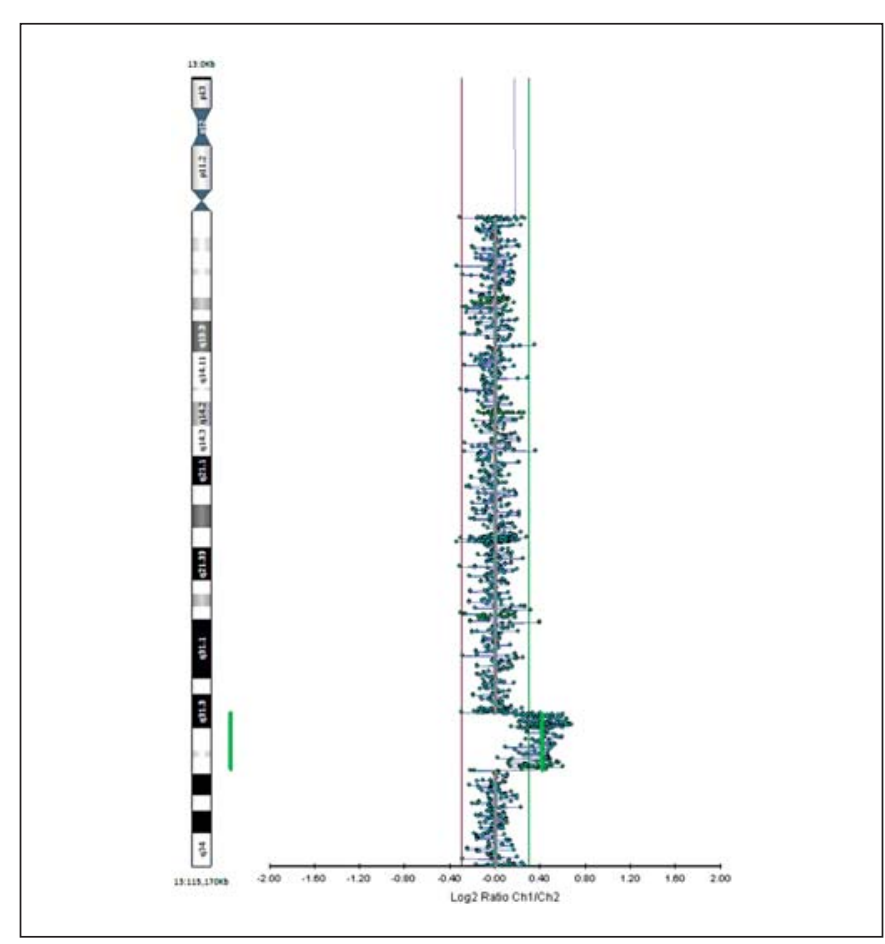

Fig. 2. $\log _{2}$ ratio plot from $60 \mathrm{~K}$ oligonucleotide arrayCGH for chromosome 13, highlighting an 8.4-Mb duplication (green bar) between basepairs $92,776,868$ and 101,047,505 - with breakpoints $13 \mathrm{q} 31.3$ and $13 \mathrm{q} 32.3$, seen in the proband and his father.

gene [Huang et al., 2010], we applied the same rationale to duplication. Albeit nonempirical, we assume it only reasonable to expect that $\mathrm{HI}$ scores are more successful predictors of pathogenicity (for duplications) compared to only the size of the interval or the number of genes within the interval. Genes with a relative high HI score $(<15)$ were scrutinised for previous reference in the literature associated with cytogenetic or arrayCGH dupli- cation (the score of $<15$ was selected due to the spread of HI scores exhibited across all of the duplicated genes) and 7 genes were chosen to be scrutinised for further discussion (table 1). Of these 7 genes, PCCA, STK24, SOX21, and HS6ST3 were not deemed important for further discussion (either due to the known function of the gene, or its function only being described in lesser mammals).

Although this rationale feels commonsensical, it does have limitations. HI scores have only been validated in relation to allele loss and empirically should only be used for such. However, triplosensitive phenotypes in association with copy number gain can be clinically harder to interpret compared to copy number loss, and this method allows the laboratory scientist the opportunity to perform gene interrogation based on an established dataset (HI scores). For very large duplications containing large numbers of genes, this can be very useful.

That said, the 29 genes were also investigated for their known protein function, particularly expression in brain or neuronal tissues as well as citations in the medical_iterature associated with developmental delay, intellectual disability and/or dysmorphism. Apart from GPC5, GPC6 and ZIC2, no association was identified. IPO5 and DOK9 have been described as pathogenic candidate genes in the noninflammatory corneal disorder keratoconus; however, as our proband and his father did not present with any clinical eye problems, these genes were not investigated further. Our discussion, therefore, focuses predominantly on GPC5, GPC6 and ZIC2.

\section{Discussion}

ArrayCGH analysis has revolutionised the diagnostic pathway for children with developmental delay/learning disability and has led to an increase in diagnoses made in 
Table 2. Cases of $\operatorname{del}(13 \mathrm{q})$ reported in the literature similar in size and location to the proband's duplication (includes pure and impure duplications, detected by arrayCGH or conventional karyotyping)

\begin{tabular}{|c|c|c|c|c|c|}
\hline Reference & Duplication & Size $(\mathrm{Mb})$ & Basepairs or loci & $\begin{array}{l}\text { Other aberration } \\
\text { or rearrangement }\end{array}$ & Clinical features \\
\hline $\begin{array}{l}\text { Jobanputra et al., } \\
2012 \\
\text { Patient } 1\end{array}$ & $13 q 32.2 q 32.2$ & 0.564 & $\begin{array}{l}99,309,736- \\
99,873,865\end{array}$ & $0.384-\mathrm{Mb}$ dup at $2 \mathrm{q} 37.3$ & $\begin{array}{l}\text { 2-vessel cord on sonogram, } \\
\text { normal at birth, prenatal } \\
\text { diagnosis performed due to } \\
\text { advanced maternal age }\end{array}$ \\
\hline $\begin{array}{l}\text { Jobanputra et al., } \\
2012 \\
\text { Patient } 3\end{array}$ & $\begin{array}{l}\text { 13q22.1q33.1 } \\
\text { (noncontinuous/ } \\
\text { segmental) }\end{array}$ & 27.09 & not given & none & $\begin{array}{l}\text { developmental delay, anterior } \\
\text { temporal arachnoid cyst }\end{array}$ \\
\hline $\begin{array}{l}\text { Mathijssen et al., } \\
2005\end{array}$ & $13 q 21.31 q 31.1$ & 21 & $\begin{array}{l}\text { RP11-234023- } \\
\text { RP11-564H19 }\end{array}$ & none & \\
\hline $\begin{array}{l}\text { Menten et al., } \\
2006\end{array}$ & $\begin{array}{l}\text { 13q31q32.3 } \\
60 \% \text { mosaic } \\
(+30 \% \text { normal } \\
\text { cell line })\end{array}$ & 13.1 & $\begin{array}{l}\text { RP11-388D4- } \\
\text { RP11-564N10 }\end{array}$ & none & $\begin{array}{l}\text { autistic behaviour, } \\
\text { developmental delay, broad } \\
\text { thumbs, nasal speech, } \\
\text { strabismus, trigonocephaly }\end{array}$ \\
\hline $\begin{array}{l}\text { Sakata et al., } \\
2008\end{array}$ & 13q31-qter & \multicolumn{2}{|c|}{$\begin{array}{l}\text { Cytogenetic G-band and FISH } \\
\text { spectral karyotyping only }\end{array}$} & $\operatorname{der}(9) t(9 ; 13)(\mathrm{p} 23 ; \mathrm{q} 31)$ & $\begin{array}{l}\text { glaucoma, bilateral polydactyly, } \\
\text { eye anomalies, Kawasaki disease, } \\
\text { hydronephrosis, bilateral } \\
\text { retained testis }\end{array}$ \\
\hline
\end{tabular}

children referred to the Paediatric/Clinical Genetics services. An ongoing challenge is the interpretation of novel chromosomal imbalances where deletions and duplications can be a diagnostic conundrum. Here we report a family with paternally inherited trisomy for the region of chromosome 13 between breakpoints $13 \mathrm{q} 31.3$ and $\mathrm{q} 32.3$ in a 12 -year-old male, referred for clinical dysmorphism and developmental delay. We review previously published duplicated $13 \mathrm{q}$ cases in relation to this novel finding, which includes the genes GPC5, GPC6 and ZIC2.

Trisomy 13 has a severe clinical presentation but can present with varying phenotypic penetrance for certain abnormalities, for example, polydactyly is not always present. Trisomy for smaller regions of chromosome 13 allows for genotype-phenotype studies which can elucidate candidate genes responsible for certain phenotypes.
Two of the genes duplicated in our proband and his father are GPC5 and GPC6, 2 of the known 6 glypican family members (GPC1-GPC6). Gene structure is highly conserved across this family, with 14 cysteine residues preserved in all of the 6 family members [Veugelers et al., 1999]. Glypicans are understood to modulate activity of heparan sulphate-binding growth factors [Campos-Xavier et al., 2009; Filmus et al., 2008]. Mutations in GPC3, GPC5 and GPC6 have been linked with Simpson-GolabiBehmel syndrome, omodysplasia and spina bifida, respectively, all of which encompass defects associated with growth and/or neural regulation [Bassuk et al., 2013]. In vivo studies show glypicans to regulate signalling of Wnts, Hedgehogs (Hhs), fibroblast growth factor receptors (FGF's) and bone morphogenic proteins (BMPs) [Topczewski et al., 2001; Yan and Lin, 2007] and suggest that 
Fig. 3. The duplicated region of chromosome $13 q$ in the proband and his father (green bar) compared to patients described in the published literature (blue bars). The patient described by Menten et al. [2006] (blue-checked bar) had a 60\% mosaic duplication. The patient described by Jobanputra et al. [2012] (blue diagonally lined bar) had a segmental region of duplication. The approximate positions of the genes ZIC2, GPC5 and GPC6 are indicated with vertical arrows.

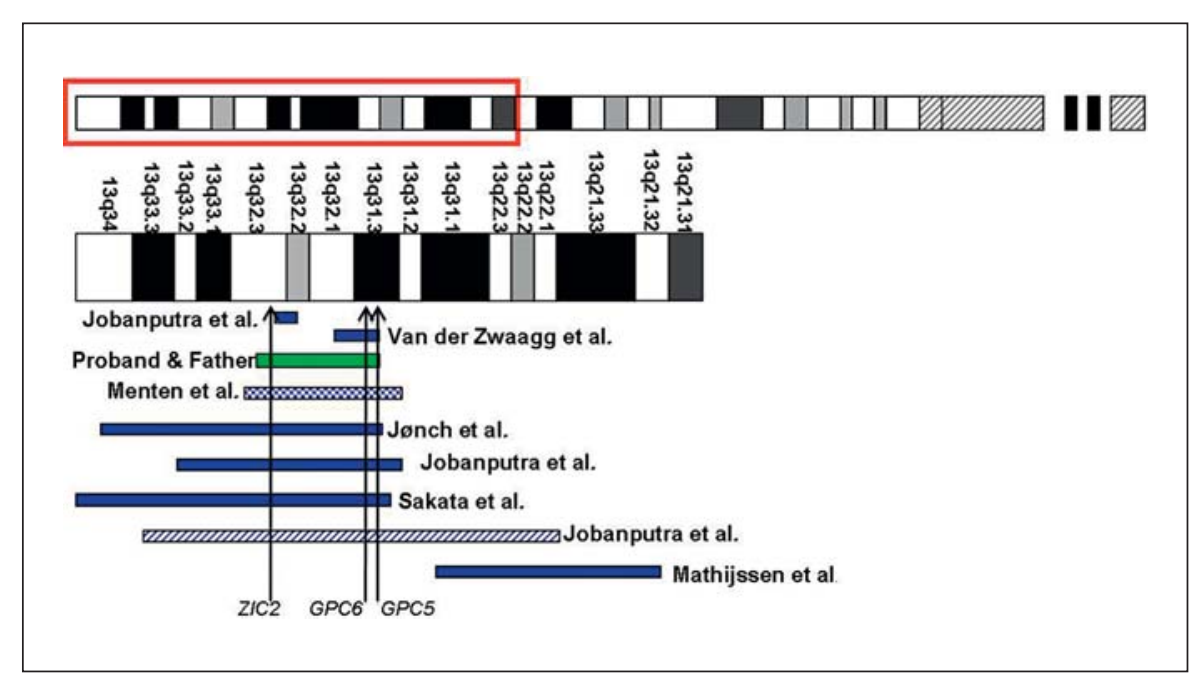

these genes may play an important role in developmental pathways.

Patient 1, described by Jobanputra et al. [2012] (table 2), had a duplication of approximately $0.564 \mathrm{Mb}$ discovered via prenatal invasive testing, performed due to advanced maternal age and a 2-vessel cord identified on sonogram. The child was healthy at birth and was seen to develop normally, although formal developmental testing was not performed. The child's duplication does not cover the GPC5 or GPC6 genes, or the SOX21 gene (located distal to GPC6) which is expressed in mammalian brain, suggesting that duplication of GPC5 and/or GPC6 may be important in developmental pathways.

van der Zwaag et al. [2009] described a 5.58-Mb duplication containing both GPC5 and GPC6 in a child with macrocephaly, broad nasal bridge, frontal bossing, and postaxial bilateral polydactyly. The group suggests GPC5 and GPC6 are candidate genes for polydactyly; however, neither our proband nor his father present with polydactyly. In comparison, our proband carries a larger duplication and presents with dysmorphic features: elongated, wide palpebral fissures, elongated columella, bilateral low-set ears, short-webbed neck, and a box-shaped body habitus.

The duplicated region we report here also includes the ZIC2 gene (fig. 3). The classical feature of holoprosencephaly seen in del(13q) is attributed to haploinsufficiency for ZIC2, the likely cause of brain malformation [Brown et al., 1998]. Holoprosencephaly due to ZIC2 mutations has a distinct face and forebrain phenotype [Solomon et al., 2010]. ZIC2 encodes a transcription factor involved in both axial and midline establishment, and in the develop- ment of the dorsal telencephalon [Cheng et al., 2006; Warr et al., 2008]. Duplications of ZIC2, however, are not reported to be associated with holoprosencephaly, and it is suggested that ZIC2 duplications alone are not responsible for developmental delay [Jobanputra et al., 2012]. This highlights that the interpretation of gene duplication compared to gene deletion can be more challenging. Indeed the ZIC2 gene has the lowest HI score of the 29 genes in our proband's duplication. This emphasises that the reasonable expectation of $\mathrm{HI}$ scores to be more successful predictors of duplication pathogenicity [compared to the size of the interval or the number of genes within the interval (see results section for further description)] should be approached with caution.

The most similar duplication described in the literature to that seen in our proband (in size and location) is described by Menten et al. [2006]. The study describes a 13.1-Mb mosaic duplication in a child with autistic behaviour, developmental delay and broad thumbs. Two other CNVs, similar in size and location to the duplication in the proband and his father in this case report are described on the DECIPHER (http://decipher.sanger. ac.uk and via email from decipher@ sanger.ac.uk) and ISCA (dbVar, http://www.ncbi.nlm.nih.gov/dbvar/) databases. DECIPHER entry CHG000221 is a $10.52-\mathrm{Mb}$ duplication between basepairs 89,678,237 and 100,197,340 (genome build GRCh37) containing, amongst others, the GPC5 and GPC6 genes. ISCA entry nssv578657_unk is an 8.32-Mb duplication between basepairs $93,865,876$ and $102,189,455$ (genome build GRCh37) and contains the GPC6 and ZIC2 genes. Developmental delay and intellectual disability are described in both cases, with further 
phenotypic information provided for DECIPHER patient CHG000221, which include broad thumbs, wide nasal bridge, anteverted nares, and long philtrum. The inheritance information has not been provided for either CNV.

Diaphragmatic hernia was reported in the father of the proband in this case report and noted in a 13q31.3q34 duplication described by Jønch et al. [2012]. Therefore, given the overlapping duplications described above and the phenotypic manifestations in our proband and his father, it appears that this duplication on $13 \mathrm{q}$ is pathogenic and mainly described in association with developmental delay, intellectual disability, facial dysmorphism, and possible presentation at birth with diaphragmatic hernia. Further case reports are required to expand on this phenotype and describe these overlapping duplications as a separate entity in the medical literature.

However, the varying clinical features between our proband and his father, in relation to previously reported cases of partial dup 13q (bearing in mind, some of these may have been ascertained by G-banding analysis), does add weight to the uncertainty surrounding novel array findings in patient cohorts with learning disability and/or developmental delay. ArrayCGH findings of unknown clinical significance can be difficult to interpret without further published material regarding the region of the genome in question. That said, variable phenotypic penetrance and clinical presentation will continue to be seen in cases of partial and full duplication and deletion of chromosome 13. Our findings should be helpful when counselling families with similar duplications or in trying to interpret prenatal array findings associated with this region of chromosome 13.

\section{Acknowledgements}

We thank the family for their participation in this report and providing their informed consent to publish this case study.

\section{References}

Bassuk AG, Muthuswamy LB, Boland R, Smith TL, Hulstrand AM, et al: Copy number variation analysis implicates the cell polarity gene glypican 5 as a human spina bifida candidate gene. Hum Mol Genet 22:1097-1111 (2013).

Brown SA, Warburton D, Brown LY, Yu CY, Roeder ER, et al: Holoprosencephaly due to mutations in ZIC2, a homologue of Drosophila odd-paired. Nat Genet 20:180-183 (1998).

-Campos-Xavier AB, Martinet D, Bateman J, Belluoccio D, Rowley L, et al: Mutations in the heparan-sulfate proteoglycan glypican 6 (GPC6) impair endochondral ossification and cause recessive omodysplasia. Am J Hum Genet 84:760-770 (2009).

Cheng X, Hsu C, Currle DS, Hu JS, Barkovich AJ, Monuki ES: Central roles of the roof plate in telencephalic development and holoprosencephaly. J Neurosci 26:7640-7649 (2006).

-Filmus J, Capurro M, Rast J: Glypicans. Genome Biol 9:224 (2008)

-Huang N, Lee I, Marcotte EM, Hurles ME: Characterising and predicting haploinsufficiency in the human genome. PLoS Genet 6:e1001154 (2010).

- Jobanputra V, Burke A, Kwame AY, Shanmugham A, Shirazi M, et al: Duplication of the ZIC2 gene is not associated with holoprosencephaly. Am J Med Genet A 158A:103-108 (2012).

Jønch AE, Larsen LG, Pouplier S, Nielsen K, Brøndum-Nielsen K, Tümer Z: Partial duplication of 13q31.3-q34 and deletion of 13q34 associated with diaphragmatic hernia as a sole malformation in a fetus. Am J Med Genet A 158A:2302-2308 (2012).

-Mathijssen IB, Hoovers JM, Mul AN, Man HY, Ket JL, Hennekam RC: Array comparative genomic hybridization analysis of a familial duplication of chromosome 13q: a recognizable syndrome. Am J Med Genet A 136:76-80 (2005).

Menten B, Maas N, Thienpont B, Buysse K, Vandesompele J, et al: Emerging patterns of cryptic chromosomal imbalance in patients with idiopathic mental retardation and multiple congenital anomalies: a new series of 140 patients and review of published reports. J Med Genet 43:625-633 (2006).

- Rivas F, Rivera H, Plascencia ML, Ibarra B, Cantú JM: The phenotype in partial $13 \mathrm{q}$ trisomies, apropos of a familial $(13 ; 15)(\mathrm{q} 22 ; \mathrm{q} 26)$ translocation. Hum Genet 67:86-93 (1984).

Sakata R, Usui T, Mimaki M, Araie M: Developmental glaucoma with chromosomal abnormalities of $9 \mathrm{p}$ deletion and $13 \mathrm{q}$ duplication. Arch Ophthalmol 126:431-432 (2008).

Schinzel A: Catalogue of Unbalanced Chromosome Aberrations in Man, ed 2. de Gruyter, Berlin (2001).

Solomon BD, Lacbawan F, Mercier S, Clegg NJ, Delgado MR, et al: Mutations in ZIC2 in human holoprosencephaly: description of a novel ZIC2 specific phenotype and comprehensive analysis of 157 individuals. J Med Genet 47:513-524 (2010)

Tharapel SA, Lewandowski RC, Tharapel AT, Wilroy RS Jr: Phenotype-karyotype correla- tion in patients trisomic for various segments of chromosome 13. J Med Genet 23:310-315 (1986).

Topczewski J, Sepich DS, Myers DC, Walker C, Amores A, et al: The zebrafish glypican knypek controls cell polarity during gastrulation movements of convergent extension. Dev Cell 1:251-264 (2001).

van der Zwaag PA, Dijkhuizen T, GerssenSchoorl KBJ, Colijn AW, Broens PMA, et al: An interstitial duplication of chromosome $13 q 31.3 q 32.1$ further delineates the critical region for postaxial polydactyly type A2. Eur J Med Genet 53:45-49 (2009).

Veugelers M, De Cat B, Ceulemans H, Bruystens AM, Coomans C, et al: Glypican-6, a new member of the glypican family of cell surface heparan sulfate proteoglycans. J Biol Chem 274:26968-26977 (1999).

-Warr N, Powles-Glover N, Chappell A, Robson J, Norris D, Arkell RM: Zic2-associated holoprosencephaly is caused by a transient defect in the organizer region during gastrulation. Hum Mol Genet 17:2986-2996 (2008).

Wei Y, Gao X, Yan L, Xu F, Li P, Zhao Y: Prenatal diagnosis and postnatal follow-up of partial trisomy $13 \mathrm{q}$ and partial monosomy 10p: a case report and review of the literature. Case Rep Genet 2012:821347 (2012).

Yan D, Lin X: Drosophila glypican Dally-like acts in FGF-receiving cells to modulate FGF signalling during tracheal morphogenesis. Dev Biol 312:203-216 (2007). 